\title{
ASSESSING THE AUTOGENOUS SHRINKAGE OF ALKALI- ACTIVATED SLAG/FLY ASH MORTAR BLENDS
}

\author{
Siva Uppalapati and Özlem Cizer
}

\begin{abstract}
Synopsis: The purpose of this study is to investigate the autogenous shrinkage of alkali-activated slag/fly ash (AASF) mortar blends. A series of tests was performed to determine the effect of type and dosage of activators on autogenous shrinkage deformation. Heat progression in AASF systems was characterized by means of isothermal calorimetry. The reaction products of alkali-activated slag/fly ash (Class F) blends was characterized using X-ray diffraction (XRD). From those results, two main phases (C-A-S-H and N-A-S-H gels) are detected in slag/fly ash blended systems and with increase in fly ash content, the amount of the C-A-S-H gel decreases and the amount of N-A-S-H gel increases. Test results show that the slag/fly ash mass ratio, type and dosage of activator are the significant factors influencing the autogenous shrinkage and rate of reaction in AASF system. With increasing fly ash content and decrease in activator-to-cementitious materials ratio, the autogenous shrinkage (up to 7 days) of the AASF system decreases.
\end{abstract}

Keywords: Alkali-activated slag/fly ash, autogenous shrinkage, chemical shrinkage, heat of hydration, mineralogical characterization, self-desiccation. 
Siva Uppalapati is a Ph.D. researcher at the Building Materials and Building Technology Division, KU Leuven, Belgium. He received his M.Sc. from Technical University Dresden, Germany and B.Tech from Acharya Nagarjuna University, India. His main research interests include early-age behavior of alkali-activated materials, in particular shrinkage deformations and numerical modelling with focus on cracking potential of alkali-activated materials.

Özlem Cizer obtained her PhD degree in Engineering at the Civil Engineering Department at KU Leuven, Belgium where she is working as a professor. She is a RILEM member, management committee member of EU COST Action TU1404, and the Editor-in-Chief of the international journal of Restoration of Buildings and Monuments. Her research focuses on carbonation in porous materials, sustainable cement-based and alkaliactivated materials, and their early-age properties, microstructure and durability.

\section{INTRODUCTION}

Concrete is one of the most widely used construction materials due to its low cost, local availability and ability to cast in any desired shapes. However, the production of portland cement, an essential consistent of concrete, is associated with a significant amount of $\mathrm{CO}_{2}$ emissions and energy usage. Altogether, the cement industry is responsible for around $3.8 \%$ of total global GHG emissions and around 5\% of total global anthropogenic $\mathrm{CO}_{2}$ emissions ${ }^{1}$. In addition to this, cement production requires large quantities of natural resources, particularly quarried limestone. It takes over 3.0 billion tons of raw material to produce the world's 2.0 billion tons of cement $^{2}$. Therefore, the research efforts have increased to develop a new alternative binder with lower energy consumption and lower $\mathrm{CO}_{2}$ footprint, while retaining or enhancing the strength and durability properties of tradition concrete. In this respect, alkali-activated materials are developed as a sustainable binder, by completely replacing cement with industrial residues (slag, fly ash), which do not require any further processing and are inherently rich in calciumsilicates and aluminosilicates that are the main chemical components found in portland Cement $^{3}$. However, using activators like sodium hydroxide and sodium silicate shows a very small Greenhouse footprint when compared to traditional concrete because such activator do not exist naturally and they are obtained from the energy intensive manufacturing process ${ }^{4}$.

The main reaction product of the alkali-activated slag comprising primarily calcium and silicates is calcium silicate hydrate (C-S-H) with $\mathrm{Al}$ in the structure, C-A-S-H gel, which differs slightly from the gel formed in cement hydration, in that it has low $\mathrm{C} / \mathrm{S}$ ratio of range around $0.9-1.2^{5}$. Recent environmental life cycle assessment (LCA) shows that alkali-activated slag (AAS) concrete has $73 \%$ lower GHGs emission, $43 \%$ less energy consumption, $25 \%$ less water usage, $22-94 \%$ lower effects for all environmental toxicity categories except a $72 \%$ higher ecotoxicity effect compare to normal portland cement ${ }^{6}$. Along with high strength and excellent performance against fire and chemical attacks, alkali-activated slag is known to have some problematical properties like fast setting time, poor workability and volume instability ${ }^{7}$ The autogenous and drying shrinkage of the alkali-activated slag is relatively much higher than normal portland cement ${ }^{8,9}$. This severe shrinkage deformation of AAS is attributed to unique behavior of the C-A-S-H gel and the pore structure $^{10}$. The hydration of alkaline systems rich in aluminosilicates such as fly ash results a three-dimensional inorganic alkaline polymer, $\mathrm{N}-\mathrm{A}-\mathrm{S}-\mathrm{H} \mathrm{gel}^{3}$ and offers the advantage of increased chemical and thermal resistance when compare to $\mathrm{C}-\mathrm{S}-\mathrm{H}$ formed during cement hydration ${ }^{3}$. From literature, low calcium fly ash-based geopolymers show relatively low shrinkage and have good mechanical properties compare to normal portland cement ${ }^{11}$. However, fly ash-based geopolymers require elevated curing temperature to obtain low shrinkage and high compressive strength, which results in significant energy consumption, thus contributing to increased environmental issues ${ }^{12}$.

Recently, the synthesis of alkali-activated binder based on GBFS and fly ash (FA) has become more attractive, as this binary system is counterbalancing the disadvantages (e.g. shrinkage) exhibited in case of alkali-activation of precursor materials individually. One of the dominating factors effecting the properties of alkali-activated slag/fly ash blends is the mass ratios of GBFS and FA ${ }^{13}, 14$. Increase in GBFS content contributes to a faster rate of strength development. Nevertheless, high GBFS results in significant conundrums such as fast setting and volume instability, inducing a higher risk to early-age micro-cracking and thereby endangering the mechanical and durability performance. On the other hand, increasing low calcium fly ash (Class F) content reduces the early-age shrinkage deformation and increase the setting time due to its low reactivity ${ }^{15}$.

The purpose of this study is to investigate the influence of type and dosage of alkaline solution on autogenous deformation of alkali-activated slag/low calcium fly ash blended systems and its relation with the reaction kinetics and reaction products. 


\section{RESEARCH SIGNIFICANCE}

Many previous studies investigate the reaction process, microstructural development, strength properties and drying shrinkage (via length change) of alkali-activated slag or fly ash or combination of both with different type and dosage of activators. However, there is no comprehensive study on autogenous shrinkage deformation and its relation with reaction kinetics and hydration products. Therefore, it is essential to present and evaluate hypotheses explanation about the autogenous shrinkage deformation of alkali-activated slag/fly ash blends and its relation with reaction kinetics and reaction products, which remains as a crucial research gap in the literature.

\section{Materials and mix composition}

\section{EXPERIMENTAL PROCEDURE}

The primary materials used in this study are Ground Granulated Blast Furnace Slag (GGBFS) and classifed low calcium fly ash (Class $\mathrm{F}$ ) with a mean diameter of $20 \mu \mathrm{m}$. The basicity coefficient $\mathrm{K}_{\mathrm{b}}=$ $\left(\mathrm{CaO}+\mathrm{MgO}+\mathrm{Fe}_{2} \mathrm{O}_{3}+\mathrm{K}_{2} \mathrm{O}+\mathrm{Na}_{2} \mathrm{O}\right) /\left(\mathrm{SiO}_{2}+\mathrm{Al}_{2} \mathrm{O}_{3}\right)$ and the hydraulic modulus $\mathrm{HM}=\left(\mathrm{CaO}+\mathrm{MgO}+\mathrm{Al}_{2} \mathrm{O}_{3}\right) / \mathrm{SiO}_{2}$ of the GGBFS were 1.0 and 1.65, respectively. The chemical composition of GGBFS and FA, determined from Xray Fluorescence (XRF) are given in Table 1 and particle size distribuation by means of laser diffraction is shown in Fig 1.

The activators used in this study were Sodium Hydroxide pellets ( $99 \%$ purity) and Sodium Silicate solution $\left(\mathrm{Na}_{2} \mathrm{O}-8.3 \%, \mathrm{SiO}_{2}-27.5 \%, \mathrm{H}_{2} \mathrm{O}-64.2 \%\right)$ with alkali modulus $\left(\mathrm{SiO}_{2} / \mathrm{Na}_{2} \mathrm{O}\right)$ of 3.4. The alkali-solutions were formulated by blending the sodium silicate with sodium hydroxide $(50 \%$ Sodium silicate $+50 \% 5 \mathrm{M}$ Sodium hydroxide) to achieve activator modulus $\left(\mathrm{M}_{\mathrm{s}}=\mathrm{SiO}_{2} / \mathrm{Na}_{2} \mathrm{O}\right)$ of 1.28 . The $5 \mathrm{M}$ Sodium hydroxide $(5 \mathrm{X} 40=200 \mathrm{~g}$ of $\mathrm{NaOH}$ pellets per liter) is prepared in distilled water at least 24 hours before use.

Alkali-activated slag/fly ash blend mortars were prepared with different mass ratio of GGBFS and FA materials and with standard 1:3 binder to sand ratio. The mix compositions of slag and fly ash were 100\%:0\%, 75\%:25\%, 50\%:50\%, 25\%:75\% and 0\%:100\%, respectively. The description of slag/fly ash blends, in terms of $\mathrm{SiO}_{2} / \mathrm{Al}_{2} \mathrm{O}_{3}$ ratios and $\mathrm{CaO}$ content are given in Table 2. As evident from Table 2, increase in fly ash content significantly decreases the $\mathrm{SiO}_{2} / \mathrm{Al}_{2} \mathrm{O}_{3}$ ratio and $\mathrm{CaO}$ content. To ensure the similar consistency for slag/fly ash blends given in Table 2, the flow test was performed on the fresh mortars after mixing, and adjustment to the alkali activatorto- cementitious materials ratio were made as needed to achieve a similar flow of $100 \%$. Three series of mix compositions were investigated in this study with different type and dosage of activators as given in Table 3.

\section{Testing methods}

Isothermal conduction calorimetry - Hydration kinetics, which describes the rate of reaction products formations, are studied by means of isothermal conduction calorimetry (TAM Air device TA Instruments), where heat generation by the exothermic hydration reaction is used as an indication of reaction progress. Alkaliactivated slag/fly ash blend paste is prepared and transferred to a small ampoule (around 8-10 g [0.0176-0.022 lbs]) and then inserted in to the calorimeter at $20^{\circ} \mathrm{C}$. The raw materials (GGBFS and FA) and alkali-solutions are stored and mixed in a temperature control room in order to maintain the temperature of the mixer close to the measured temperature $\left(20^{\circ} \mathrm{C}\right)$.

Characterisation of reaction products - X-ray diffraction (XRD, Bruker 2D PHASER) analysis is used to indicate which mineral phases are involved in the binder formation and which crystalline phases are formed at the age 7 days. X-ray diffraction patterns were collected in the $2 \theta$ range of 10 to $70^{\circ}$ with step size of $0.02^{\circ}$ and step time of $0.3 \mathrm{~s}$, and $\mathrm{CuK} \alpha$ radition of $30 \mathrm{KV}$ and $10 \mathrm{~mA}$.

Autogenosus shrinkage deformation - Autogenous shrinkage deformation in mortars scale was tested via auto-shrink digital dilatometer (upto 7 days), which is typically used for cement research. This set-up is composed of corrugated polyethylene cylindrical moulds that encapsulate the fresh material while minimizing restraint, thereby permitting measurements after mixing. Two corrugated polyethylene cylindrical molds 1.15 in. [29 mm] in diameter and $16.5 \mathrm{in} .\left[420 \mathrm{~mm}\right.$ ] in length were casted and tested at room temperature $20^{\circ} \mathrm{C}$ for each mix composition.

\section{Reaction kinetics}

\section{EXPERIMENTAL RESULTS AND DISCUSSION}

The effect of slag/fly ash mass ratios with different type and dosage of activators on the reaction kinetics investigated up to 72 hours at constant $20^{\circ}$ was discuss in this section using Fig. 2-4. The entire reaction process of alkali-activated slag/fly ash blend systems can be divided into four stages, namely initial dissolution, induction, acceleration/deceleration and stable period ${ }^{16}$. Within a few minutes after mixing raw materials with 
alkaline solution, the dissolution stage occurs with a high amount of heat release due to initial wetting, dissolution of the slag materials ${ }^{17}$ and also partly due to the formation of initial reaction products from the dissolved units such as $\mathrm{Si}, \mathrm{Ca}$, and $\mathrm{Na}$ in the alkali-solution ${ }^{18}$. The newly-formed reaction products grow rapidly and form a layer on the surface of the unreactive particles, which limit the available alkalis for dissolution of the raw materials and temporarily hinder the reaction process (induction period). Further reaction continues, when the alkalis supplied from the activators penetrate through the formed layer and reaches the unreactive particles. Then the second peak (acceleration peak) appears and assigned to the massive formation of reaction products ${ }^{19}$. Finally, after completing the main reaction, the heat release decreases and remains stable (stable period).

Series1-Effect of slag and fly ash mass ratios - The heat flow of slag/fly ash blends activated with sodium silicate + sodium hydroxide up to 72 hours is shown in Fig. 2(a). All mixtures show high exothermic peaks immediately after mixing, followed by the induction period. Initial heat release peak in dissolution stage is not shown completely in Fig. 2(a) due to its much higher magnitude. It was observed that the initial peaks of AASF systems in the dissolution stage appears around at 3-5 min and increasing the fly ash content results in lower dissolution peaks, which demonstrates that the dissolution of the fly ash in alkali solution is slower than the slag. From Fig. 2(a), an increase in fly ash content shows considerably longer induction periods due to its low reactivity and it may mainly function as a nucleation site for the reaction products and has a negative contribution to the further reaction between alkalis and slag particles ${ }^{20}$. With increase in the fly ash content, the acceleration peak intensity decreases and slightly shifts to the later times, as shown in Fig. 2(a). Such a significant change in the acceleration peak with fly ash addition is attributed to the dilution of $\mathrm{Ca}^{2+}$ ion dissolved from the surface of slag grains. In contrast, sample with $100 \%$ fly ash exhibits only one heat evolution peak with no dormant period, as shown in Fig. 2(a).

Series2-Effect of activator-to-cementitious materials ratio - The influence of activator-tocementitious materials ratio on the reaction kinetics of alkali-activated slag/fly ash blends is studied by comparing Fig. 2(a) and Fig. 3(a). It can be observed that there is no significant change in the time of first dissolution peak with decrease in activator-to-cementitious materials ratio because the dissolution stage is more likely a physical rather than a chemical process ${ }^{20}$. However, the intensity of the acceleration peak increases with decrease in dosage of activator and slight shift towards the lower time (by comparing Fig. 2(a) \& 3(a) for each slag/fly ash mass ratio respectively) due to lower degree of dilution of slag and fly ash in pore solution.

Series3-Sodium hydroxide activated slag/fly blends - The hydration heat evolution of alkaliactivated slag/fly ash blends with 5M_sodium hydroxide is shown in Fig. 4(a). Only one major peak was observed in the calorimetric data for sodium hydroxide activated slag/fly ash blends, which occurs immediately after the addition of activators. As slag content decreases and fly ash content increases, the first peak associated with initial wetting and dissolution of slag and fly ash particles, decreases as shown in Fig. 4(a). However, for the sample with more fly ash content (slag/fly ash: 25/75,0/100), the initial dissolution peak occurs immediately after mixing (around $15 \mathrm{~min}$ ) with higher intensity and also the duration of the peak was very short compare to mixes with high slag content.

The cumulative heat evolutions of slag/fly ash blends activated with a sodium hydroxide and sodium silicate are shown in Fig. 2-4(b). The first dramatic increase is associated with the initial wetting and dissolution of slag and fly ash in the alkali solutions; followed by moderate increase corresponding to the induction period; the further increase is assigned to the acceleration stage. The heat of hydration decreases with increase in fly ash content ash as shown in Fig. 2(b). Comparing the cumulative heat flow of sodium hydroxide (5M) and combination of sodium hydroxide and sodium silicate activated slag/fly ash blends, it is apparent that combine sodium hydroxide and sodium silicate activator solution exhibits a higher degree of reaction. When sodium silicate is blended with sodium hydroxide, the $\mathrm{pH}$ value reduces and the dissociation of calcium ions increases. As a result, the presence of sodium silicate results in greater overall heat evolution and product formation ${ }^{21}$.

\section{Characterization of the alkali-activated slag/fly blend binders}

Starting materials - Mineralogical characterization of the starting materials, GGBFS and FA, carried out by $\mathrm{X}$ ray powder diffraction is shown in Fig. 5. Both GGBFS and FA consisted mainly of an amorphous phases indicated with a broad hump in the interval of $25-35^{\circ}$ in angle $2 \theta$ for the GGBFA and $15-40^{\circ}$ in case of fly ash. The difference in the location of humps was associated with the structural difference in the amorphous glasses present in individual materials. As shown in Fig. 5, fly ash contain some crystalline phases such as quartz, mullite and hematite.

Mineralogical characterization of the binders - Fig. 6 shows the X-ray diffraction (XRD) patterns of 
slag/fly ash blends activated with $50 \%$ of sodium hydroxide $+50 \%$ of sodium silicate solutions at the age of 7 days. Mineralogical analysis on hydrated pastes shows the formation of different reaction products, which varied depending up on the slag and fly ash mass ratios. The main phases identified in alkali-activated slag is CS-H gel as shown in Fig. 6. In activated-fly ash paste, the halo attributed to the vitreous phase in the initial ash shifts to slightly higher angular values $\left(2 \theta=25-40^{\circ}\right)$. This effect is indicating the formation of a sodium aluminosilicate hydrate (N-A-S-H) gel of amorphous nature and three-dimensional network ${ }^{22}$. In alkalineactivated slag/fly ash blend (AASF), both C-S-H and aluminosilicate hydrate phases are detected clearly and with increase in fly ash content, a peak around $29^{\circ}$ in $2 \theta$ was broader and its intensity was lower, indicating that the amount of C-S-H gel decreases. Similarly, the width of halo at $25^{\circ}-27^{\circ}$ in $2 \theta$ becomes larger, meaning that the presence of sodium aluminosilciate $(\mathrm{N}-\mathrm{A}-\mathrm{S}-\mathrm{H})$ increases with increase in fly ash content. The crystalline phases quartz, mullite and hematite detected in the initial material remains apparently unaltered with the activation. With increasing the fly ash content, the peak intensity of the crystalline phases increases as shown in Fig. 6. The mineralogical characterization of slag/fly ash blends, activated with sodium hydroxide (5M) shows similarly phases as in combined sodium silicate and sodium hydroxide activated system. An additional based reflection at $12^{\circ}$ in $2 \theta$ is observed in AASF blends activated with $\mathrm{NaOH}$, indicating a crystalline phase, hydrotalcite $\left(\mathrm{Mg}_{6} \mathrm{Al}_{2} \mathrm{CO}_{3} \mathrm{OH}_{16} 4 \mathrm{H} 2 \mathrm{O}\right)$, as shown in Fig. 7.

\section{Autogenous Shrinkage}

Early-age autogenous shrinkage deformation is a physico-chemical phenomenon resulted from the chemomechanical and hydro-mechanical interactions within the hardening cementitious matrix ${ }^{23}$. The chemomechanical deformation known as Le Chatelier contraction (chemical shrinkage) developed due to the negative balance between the absolute density of hydrates and those of cementitious materials and water, while the hydro-mechanical deformation, known as self-desiccation shrinkage, results from the development of internal stresses within the matrix due to the consumption of pore water by hydration ${ }^{23}$. The autogenous shrinkage of the alkali-activated slag/fly ash blend systems with different type and dosage of activators is shown in Fig. 8-10.

Series1-Effect of slag and fly ash mass ratios - Fly ash contains more inactive minerals and also its active constituents are mainly hollow glass spheres, which are not as reactive as glassy phase of slag at early ages $^{24}$. As a result, the reactivity of alkali-activated slag/fly blend systems decreases with increase in fly ash content as shown in Fig. 2 and thus the autogenous deformation related to the chemical shrinkage decreases with increases in fly ash content. In addition to this, with increase in the fly ash content and decrease in slag content, the $\mathrm{Ca}^{+2}$ ion concentration decreases (Table 2) and contributes to the formation of less C-A-S-H gel. As shown in Fig. 6, the peak at $29^{\circ}$ in $2 \theta$ was boarder and its intensity lower with increase in fly ash content, indicating that the amount of $\mathrm{C}-\mathrm{A}-\mathrm{S}-\mathrm{H}$ gel formation decreases with increases in fly ash content. This may results in formation of less dense matrix and lower mesopore volume, which is related to self-desiccation resulting from a decrease in the relative humidity of the capillary pores ${ }^{22}$. Thus, the autogenous shrinkage related to selfdesiccation decreases with increases in fly ash as shown in Fig. 8.

Series2-Effect of activator-to-cementitious materials ratio - The effect of activator-to-cementitious materials ratio on the autogenous shrinkage of alkali-activated slag/fly blends is studied by comparing Fig.8 and Fig.9. By decreasing the activator-to-cementitious materials ratio, the corresponding $\mathrm{Na}_{2} \mathrm{O}$ and $\mathrm{SiO}_{2}$ concentrations decrease, as shown in Table 3. As a result, the hydration of slag/fly ash blends decreases with decrease in activator-to-cementitious materials ratio (by compare Fig.2 and Fig.3 for each slag/fly ash mass ratio respectively) and thus the autogenous deformation related to the chemical shrinkage decreases. In contrast, mortar samples with high fly ash content (slag/fly ash: 25/75 and 0/100) result in higher autogenous shrinkage with a decrease in dosage of activator. The reason may assumed as follows: in addition to decrease in $\mathrm{Na}_{2} \mathrm{O}$ and $\mathrm{SiO}_{2}$ concentration, the corresponding water content also decreases with decrease in activator-to-cementitious materials ratio as shown in Table 3. Decrease in water content may causes to decrease the pore sizes, which is directly related with the shrinkage due to self-desiccation ${ }^{25}$. Therefore, it may concluded that the autogenous shrinkage in highly fly ash content mixes with water-to-cementitious material ratio below 0.42 occurred mainly due to self-desiccation in hardened state rather than the chemical shrinkage in fresh state.

Series3-Sodium hydroxide activated slag/fly blends - Fig. 10 shows the autogenous shrinkage of alkali-activated slag/fly ash blends with $\mathrm{NaOH}(5 \mathrm{M})$. Similar to the previous research work ${ }^{26}$, the sodium hydroxide activated slag/fly ash blends exhibited a relatively faster reaction rate during the early hours of reaction, which decreases with increases in fly ash content and decreases in dosage of activator (Fig. 4(a)). As a result, the autogenous shrinkage increases sharply at the beginning hours and reaches a steady state as shown in Fig. 10. However, the mortar containing only fly ash shows relatively much higher autogenous shrinkage due to 
its large chemo-mechanical deformation at early-age.

\section{CONCLUSIONS}

The influence of slag/fly ash mass ratio, activator type and concentration on the early age reactions kinetics, hydration products and autogenous shrinkage were evaluated and the following conclusions are drawn:

- High fly ash content in slag/fly ash blended system, results in lower heat evolution and increases the duration of the induction period, due to lower reactivity of fly ash at early ages. The dosage of activator does not shown any significant effect on the initial dissolution peak, whereas the intensity of acceleration peak increases with decreases in activator-to-cementitious materials ratio. While, the sodium hydroxide activated slag/fly ash shows only one peak, associated with initial dissolution of slag and fly ash in alkali solution.

- The main reaction products in alkali-activated slag/fly ash blends activated with sodium hydroxide and sodium silicates are calcium silicate hydrate (C-S-H gel) with Al substitution in the structure and sodium aluminosilicate hydrate (N-A-S-H). With increasing the fly ash content, the amount of C-A-S$\mathrm{H}$ gel decreases and N-A-S-H hydrate increases. An additional peak appears with sodium hydroxide activator at $7^{\circ}$ in $2 \theta$, indicating a crystalline phase, hydrotalcite. The magnitude of the crystalline phase detected in slag/fly ash blend systems increases with increases in fly ash content.

- Slag/fly ash mass ratios shows a significant effect on the autogenous shrinkage which decreases with increase in fly ash content due to its low reactivity at early ages. It is proposed that decrease in activator-to-cementitious materials ratio below 0.55 , results in higher autogenous shrinkage due to decrease in pore size and relative humidity. Whereas in sodium hydroxide activated system, the autogenous shrinkage increases dramatically in early hours and becomes steady with age.

\section{REFERENCES}

[1] Barcelo L., Kline J., Walenta G., Gartner E., Cement and carbon emission, Materials and structures, 2014, V. $47: 1055-1065$.

[2] Pacheco-T.F., Labrincha.J.A., Leonelli.C., Palomo.A., Chindaprasirt.P., Handbook of Alkali-actiavted Cements, Mortars, and concrete, Elsevier, 2015, pp - 19.

[3] Shi, C, Krivenko, P.V., Roy, D.M., Alkaline-activated cements and concretes, Taylor and Francis, 2006, NY.

[4] Duxson P., Fernández-Jiménez A., Provis J.L., Lukey G.C., Palomo A. and van Deventer J.S.J. (2007a), 'Geopolymer technology: the current state of the art', Journal of Materials Science, V. 42, 2917-2933.

[5] Myers, R.J., Bernal, S.A., San Nicolas, R., Provis, J.L.: Generalized structural description of calcium-sodium aluminosilicate hydrate gels: the cross linked substituted tobermorite model, Langmuir 29 (17), 5294-5306 (2013).

[6] Mohan. J., Chen, X., Rajabipour, F., and Hendrickson, C. T. "Comparative life cycle assessment of conventional, glass powder, and alkali-activated slag concrete and mortar, American Society of Civil Engineers, 2014.

[7] D. Križan, B. Živanović, Effects of dosage and modulus of waterglass on early hydration of alkali-slag cements, Cement Concrete Research, V.32 (2002), 1181-1188.

[8] F. Collins, J.G. Sanjayan, Effect of pore size distribution on drying shrinkage of alkali-activated slag concrete, Cement Concrete Research, V. 30, (2000), 1401-1406.

[9] A.A. Melo Neto, M.A. Cincotto, W.Repette, Drying and autogenous shrinkage of pastes and mortars with activated slag cement, Cement Concrete Research, V. 38, 2008, 565-574.

[10] Thomas R.J., Hailong. Y, Aleksandra. R., Sulapha. P., Alkali-activated slag cement concrete, Concrete International V.38, PP 33-38, ACI.

[11] F.Winnefeld, A.Leemann, M.Lucuk, P.Svoboda, M.Neuroth, Assessment of phase formation in alkaliactivated low and high calcium fly ashes in building materials, Construction and Building Materials, 24 (2010) 
1086-1093.

[12] G.Kovalchuk, A.Fernandez-Jimenez, A.Palomo, Alkali-activated fly ash: effect of thermal curing conditions on mechanical and microstructural development - Part II, Fuel 86(2007)315-322.

[13] Puertas, F., Fernandez-Jimenez, A., 2003. Mineralogical and microstructural characterization of alkaliactivated fly ash/slag pastes. Cement Concrete Composites, V. 25, 287-292.

[14] Puertas, F., Martinez-Ramirez, S., Vazquez, T., Alonso, S., 2000. Alkali-activated fly ash/slag cement strength behavior and hydration products, Cement Concrete Research, V. 30, 1625-1632.

[15] J.G. Jang, N.K.Lee, H.K.Lee, Fresh and hardened properties of alkali- activated fly ash/slag pastes with superplasticizers, Construction and Building Materials, V. 50, 2014, 169-176.

[16] S. Chithiraputhiran, N. Neithalath, Isothermal reaction kinetics and temperature dependence of alkali activation of slag, fly ash and their blends, Construction and Building Materials. 45 (2013) 233-242.

[17] Ravikumar D, Neithalath N. Reaction kinetics in sodium silicate powder and liquid activated slag binders evaluated using isothermal calorimetry, Thermomchica Acta 2012;546:32-43.

[18] Bernal SA, Provis JL, Rose V, Gutierrez RM. Evolution of binder structure in sodium silicate-activated slag-metakaolin blends, Cement and Concrete Compositions 2011;33:46-54.

[19] Shi C, Day RL. A calorimetric study of early hydration of alkali-slag cements. Cement Concrete Research 1995;25:1333-46.

[20] Gao. X., Yu. Q.L., Brouwers H.J.H., Reaction kinetics, gel characterization and strength of ambient temperature cured alkali activated slag/fly ash blends, Construction and Building materials, 80, 2015, 105-115.

[21] Zivica V. Effects of type and dosage of alkaline activator and temperature on the properties of alkaliactivated slag mixtures, Construction and Building materials 2007, 21(7):1463-9.

[22] Maria. C., Willian. A., Isabel. S., Microstructural and Mechanical properties of Alkali Activated Colombian Raw Materials, Materials, 2016.

[23] Mounanga P, Bouasker M, Pertue A, Perronnet A, Khelidj A. Early-age autogenous cracking of cementitious matrices: physico-chemical analysis and micro/macro investigations. Materials and Structures, 2011; 44(4):749-72.

[24] Yonghao Fang, Y.Gu and Q. Kang, "Effect of fly ash, Mgo and curing solution on the chemical shrinkage of Alkali-activated slag cement”, Advance Material Research, Vol. 168-170, PP 2008-2012.

[25] Lee. N.K., Jang. J.G and Lee. H.K., Shrinkage characteristics of alkali-activated fly ash/slag paste and mortar at early-age, Cement and concrete compositions. 53 (2014) 239-248.

[26] Berhan. S.G., Sulapha P., Role of activators type and dosage on the reaction kinetics of alkali-activated slag pastes, third internal conference on sustainable construction materials and technologies.

Table. 1-Chemical compositions of binder materials (mass \%).

\begin{tabular}{|c|cccccccc|}
\hline Materials & $\mathbf{S i O}_{2}$ & $\mathbf{A l}_{2} \mathbf{O}_{3}$ & $\mathbf{F e}_{2} \mathbf{O}_{3}$ & $\mathbf{C a O}$ & $\mathbf{M g O}$ & $\mathbf{S O}_{3}$ & $\mathbf{M n O}$ & $\mathbf{K}_{2} \mathbf{O}$ \\
\hline GGBFS & 36.190 & 12.410 & 0.600 & 39.80 & 7.250 & - & 0.320 & 0.490 \\
Fly ash & 54.460 & 26.460 & 6.630 & 3.500 & 2.000 & 1.260 & 0.089 & 2.900 \\
\hline Materials & $\mathbf{T i O}_{2}$ & $\mathbf{V}_{2} \mathbf{O}_{\mathbf{5}}$ & $\mathbf{S r O}$ & $\mathbf{Z r O}_{2}$ & $\mathbf{C r}_{2} \mathbf{O}_{3}$ & $\mathbf{Z n O}$ & $\mathbf{S r O}$ & - \\
\hline GGBFS & 1.070 & 0.019 & 0.092 & 0.049 & - & - & 0.092 & - \\
Fly ash & 1.130 & 0.065 & 0.135 & 0.037 & 0.028 & 0.030 & 0.135 & - \\
\hline
\end{tabular}


Table. 2- Slag/fly ash blends in terms of $\mathrm{SiO}_{2} / \mathrm{Al}_{2} \mathrm{O}_{3}$ ratios and $\mathrm{CaO}$ content.

\begin{tabular}{|l|c|c|c|c|}
\hline \multirow{2}{*}{ S.No } & Slag/ fly ash blends mix compositions & \multirow{2}{*}{ CaO (wt \%) } & \multirow{2}{*}{ SiO $_{2} / \mathbf{A l}_{2} \mathbf{O}_{3}$ ratio } \\
\cline { 2 - 3 } & GGBFS (wt \%) & Fly ash (wt \%) & 39.8 & 2.91 \\
\hline 1 & 100 & 0 & 30.7 & 2.55 \\
\hline 3 & 75 & 25 & 21.6 & 2.33 \\
\hline 4 & 50 & 50 & 12.5 & 2.17 \\
\hline 5 & 25 & 75 & 3.5 & 2.05 \\
\hline
\end{tabular}

Table. 3- Mix proportions of alkali-activated slag/fly ash blends.

\begin{tabular}{|c|c|c|c|c|c|c|}
\hline \multicolumn{2}{|c|}{ GGBFS: FS } & 100:0 & $75: 25$ & $50: 50$ & $25: 75$ & $0: 100$ \\
\hline \multirow{6}{*}{ Series 1} & Activator type & $\mathrm{A}$ & $\mathrm{A}$ & $\mathrm{A}$ & $\mathrm{A}$ & A \\
\hline & $\mathrm{A} / \mathrm{B}$ ratio & 0.70 & 0.70 & 0.70 & 0.70 & 0.70 \\
\hline & $\mathrm{M}_{\mathrm{s}}$ & 1.28 & 1.28 & 1.28 & 1.28 & 1.28 \\
\hline & $\% \mathrm{SiO}_{2}$ & 9.60 & 9.60 & 9.60 & 9.60 & 9.60 \\
\hline & $\% \mathrm{Na}_{2} \mathrm{O}$ & 7.50 & 7.50 & 7.50 & 7.50 & 7.50 \\
\hline & $\mathrm{W} / \mathrm{B}$ & 0.53 & 0.53 & 0.53 & 0.53 & 0.53 \\
\hline \multirow{6}{*}{ Series 2} & Activator type & $\mathrm{A}$ & $\mathrm{A}$ & $\mathrm{A}$ & $\mathrm{A}$ & A \\
\hline & A/B ratio & 0.70 & 0.60 & 0.55 & 0.52 & 0.49 \\
\hline & $\mathrm{M}_{\mathrm{s}}$ & 1.28 & 1.28 & 1.28 & 1.28 & 1.28 \\
\hline & $\% \mathrm{SiO}_{2}$ & 9.60 & 8.20 & 7.50 & 7.10 & 6.68 \\
\hline & $\% \mathrm{Na}_{2} \mathrm{O}$ & 7.50 & 6.40 & 5.90 & 5.60 & 5.20 \\
\hline & $\mathrm{W} / \mathrm{B}$ & 0.53 & 0.45 & 0.42 & 0.39 & 0.37 \\
\hline \multirow{5}{*}{ Series 3} & Activator type & $\mathrm{B}$ & $\mathrm{B}$ & B & $\mathrm{B}$ & $\mathrm{B}$ \\
\hline & $\mathrm{A} / \mathrm{B}$ ratio & 0.70 & 0.60 & 0.55 & 0.52 & 0.49 \\
\hline & $\mathrm{M}_{\mathrm{s}}$ & - & - & - & - & - \\
\hline & $\% \mathrm{Na}_{2} \mathrm{O}$ & 9.10 & 7.80 & 7.20 & 6.80 & 6.40 \\
\hline & $\mathrm{W} / \mathrm{B}$ & 0.53 & 0.45 & 0.42 & 0.39 & 0.37 \\
\hline
\end{tabular}

* A $-50 \%$ of Sodium Hydroxide $(5 \mathrm{M})+50 \%$ Sodium Silicate, B - 5M_Sodium Hydroxide $\mathbf{A} / \mathbf{B}$ - Activator-to-Binder ratio, $\mathbf{M}_{\mathbf{s}}-$ Alkali Modulus $\left(\mathrm{SiO}_{2} / \mathrm{Al}_{2} \mathrm{O}_{3}\right)$.

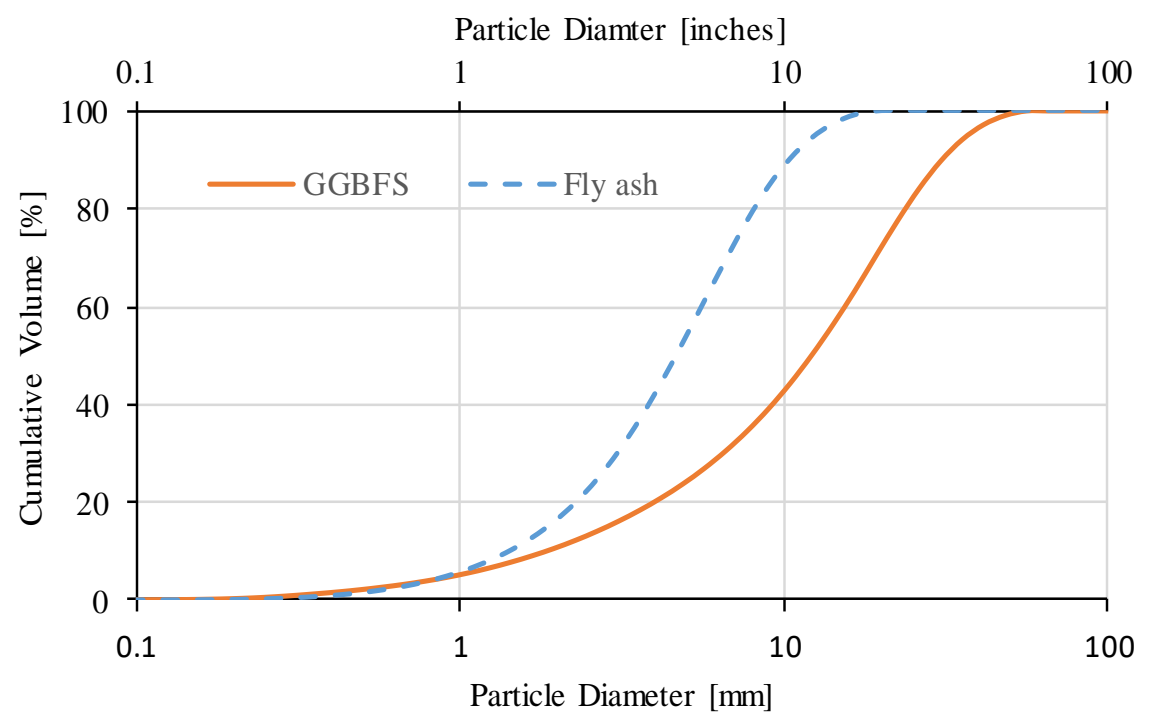

Fig. 1- Particle size distribution of GGBFS and Fly ash. 


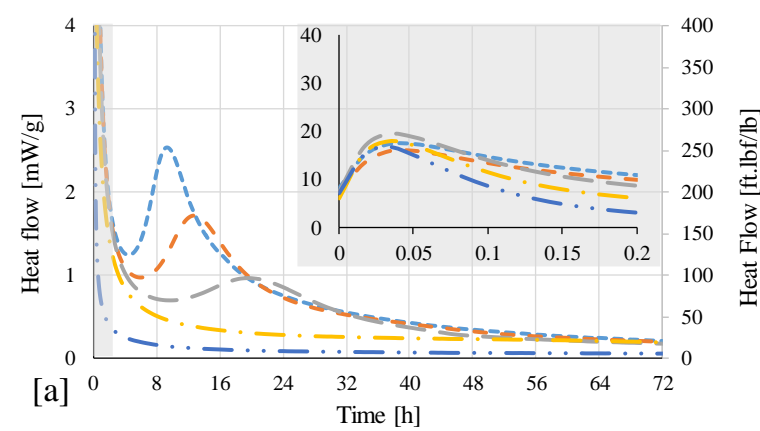

- - 100\%GGBFS : $0 \% \mathrm{FA}--75 \% \mathrm{GGBFS}: 25 \% \mathrm{FA}-{ }_{-50}-50 \mathrm{GGBFS}: 50 \% \mathrm{FA}$ - $25 \%$ GGBFS : $75 \% \mathrm{FA}-.0 \% \mathrm{GGBFS}: 100 \% \mathrm{FA}$

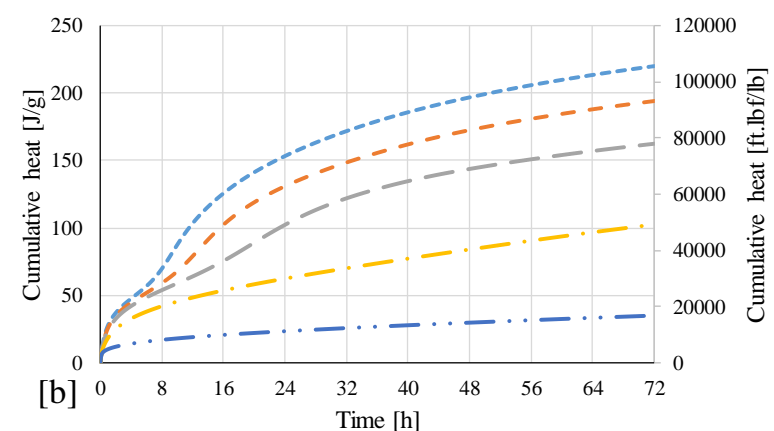

- - 100\%GGBFS : $0 \% \mathrm{FA}--75 \% \mathrm{GGBFS}: 25 \% \mathrm{FA}-50 \% \mathrm{GGBFS}: 50 \% \mathrm{FA}$ - $25 \% \mathrm{GGBFS}: 75 \% \mathrm{FA}-0 \% \mathrm{GGBFS}: 100 \% \mathrm{FA}$

Fig. 2- (a) heat flow (b) cumulative heat release curves for Series 1 mixes.

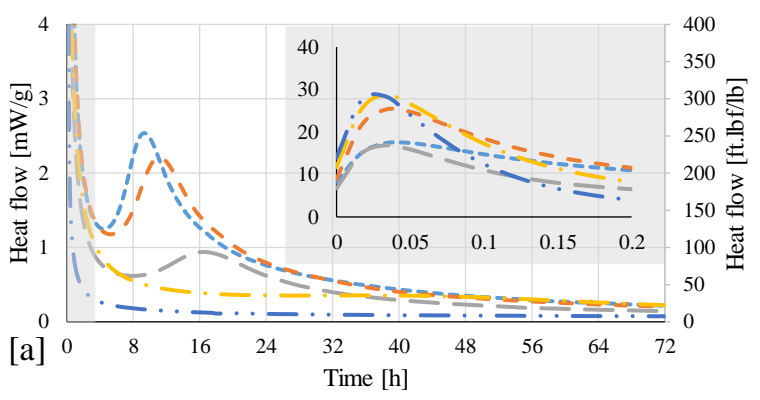

$--100 \%$ GGBFS : $0 \%$ FA_0.7A/B $\quad-\quad-75 \%$ GGBFS $: 25 \%$ FA_0.6A/B

$-50 \%$ GGBFS : $50 \%$ FA_0.55A/B $\quad-25 \%$ GGBFS : $75 \%$ FA_0.52A/B

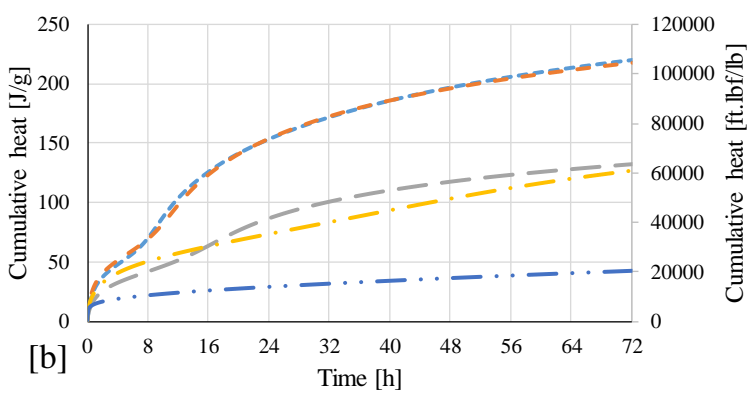

$-0-100 \%$ GGBFS : $0 \%$ FA_0.7A/B $\quad--75 \%$ GGBFS $: 25 \%$ FA_0.6A/B

- $50 \%$ GGBFS : $50 \%$ FA_0.55A/B $-.25 \%$ GGBFS : $75 \%$ FA_0.52A/B - $0 \%$ GGBFS:100\%FA_0.49A/B

Fig. 3- (a) heat flow (b) cumulative heat flow release for Series 2 mixes.

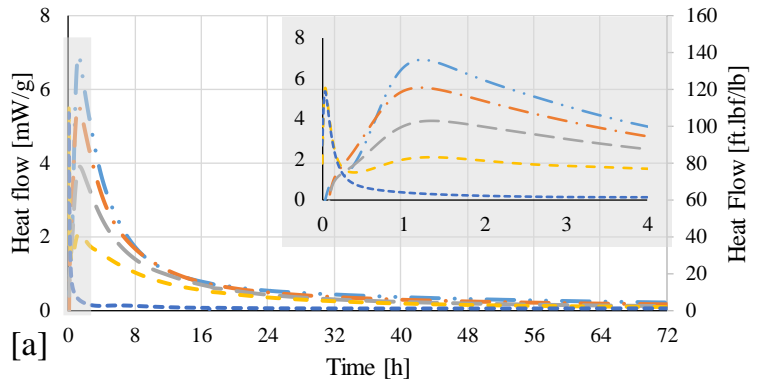

- $100 \% \mathrm{GGBFS}: 0 \% \mathrm{FA} \_0.7 \mathrm{~A} / \mathrm{B} \quad-75 \% \mathrm{GGBFS}: 25 \% \mathrm{FA} \_0.6 \mathrm{~A} / \mathrm{B}$ - 50\%GGBFS : $50 \% \mathrm{FA} 0.55 \mathrm{~A} / \mathrm{B} \quad-\quad 25 \% \mathrm{GGBFS}: 75 \% \mathrm{FA} \_0.52 \mathrm{~A} / \mathrm{B}$ - - 0\%GGBFS:100\%FA_0.49A/B

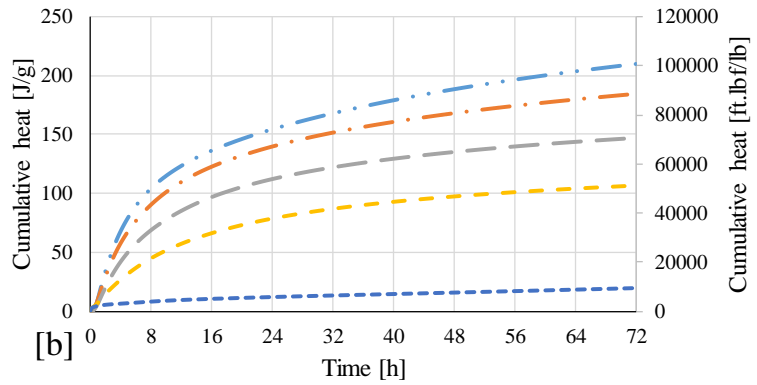

- $100 \% \mathrm{GGBFS}: 0 \% \mathrm{FA} \_0.7 \mathrm{~A} / \mathrm{B} \quad-75 \% \mathrm{GGBFS}: 25 \% \mathrm{FA} \_0.6 \mathrm{~A} / \mathrm{B}$ - 50\%GGBFS : $50 \%$ FA_0.55A/B $\quad-\quad 25 \% \mathrm{GGBFS}: 75 \% \mathrm{FA} \_0.52 \mathrm{~A} / \mathrm{B}$ - - 0\%GGBFS:100\%FA_0.49A/B

Fig. 4- (a) heat flow (b) cumulative heat flow release for Series 3 mixes. 


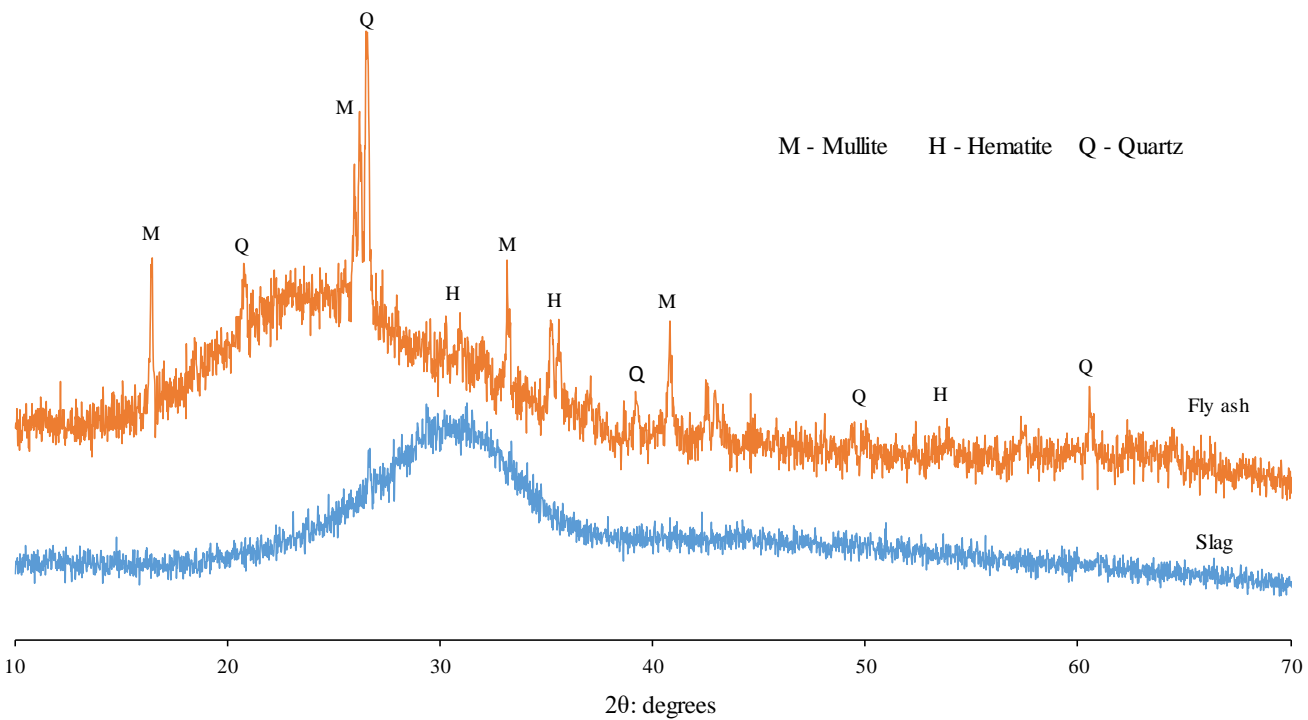

Fig. 5 - XRD patterns of binding materials, GGBFS and fly ash.

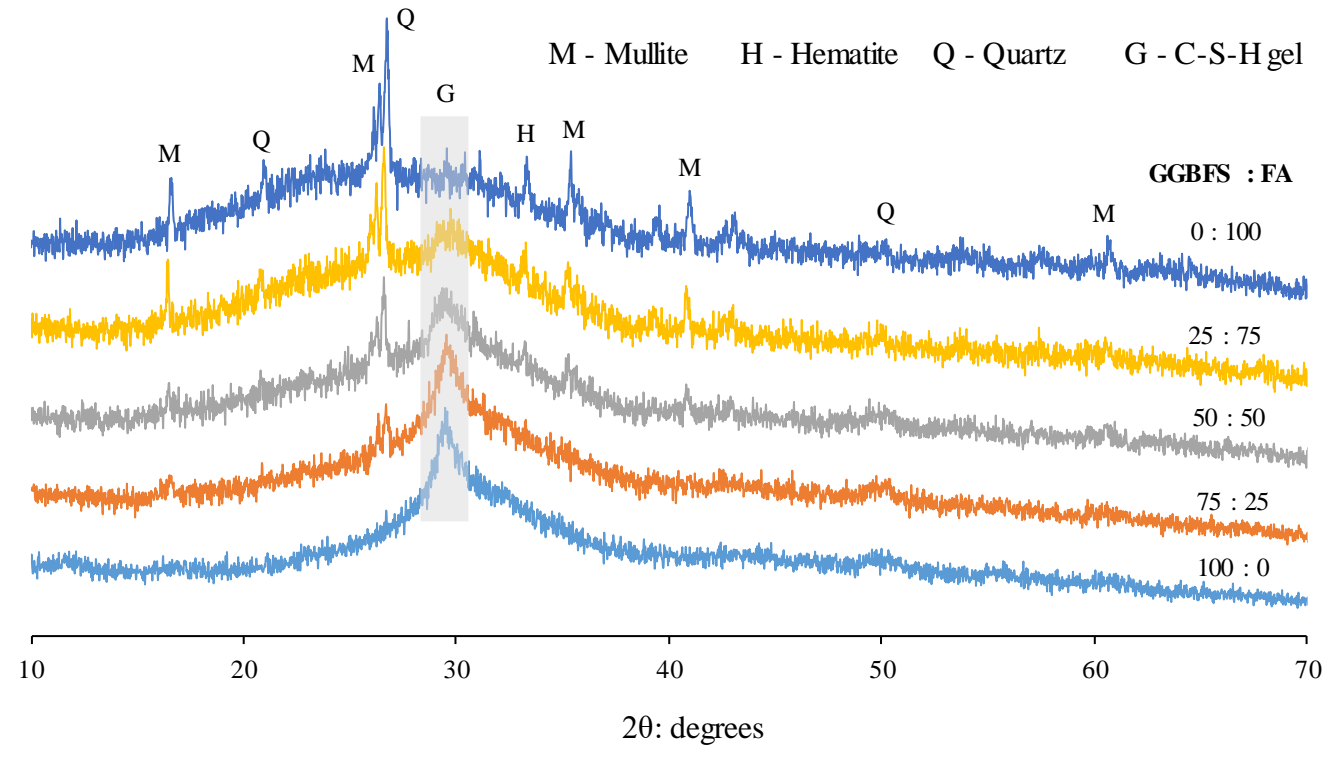

Fig. 6 - XRD patterns of slag/fly ash blends activated with 50\% sodium hydroxide $+50 \%$ sodium silicate. 


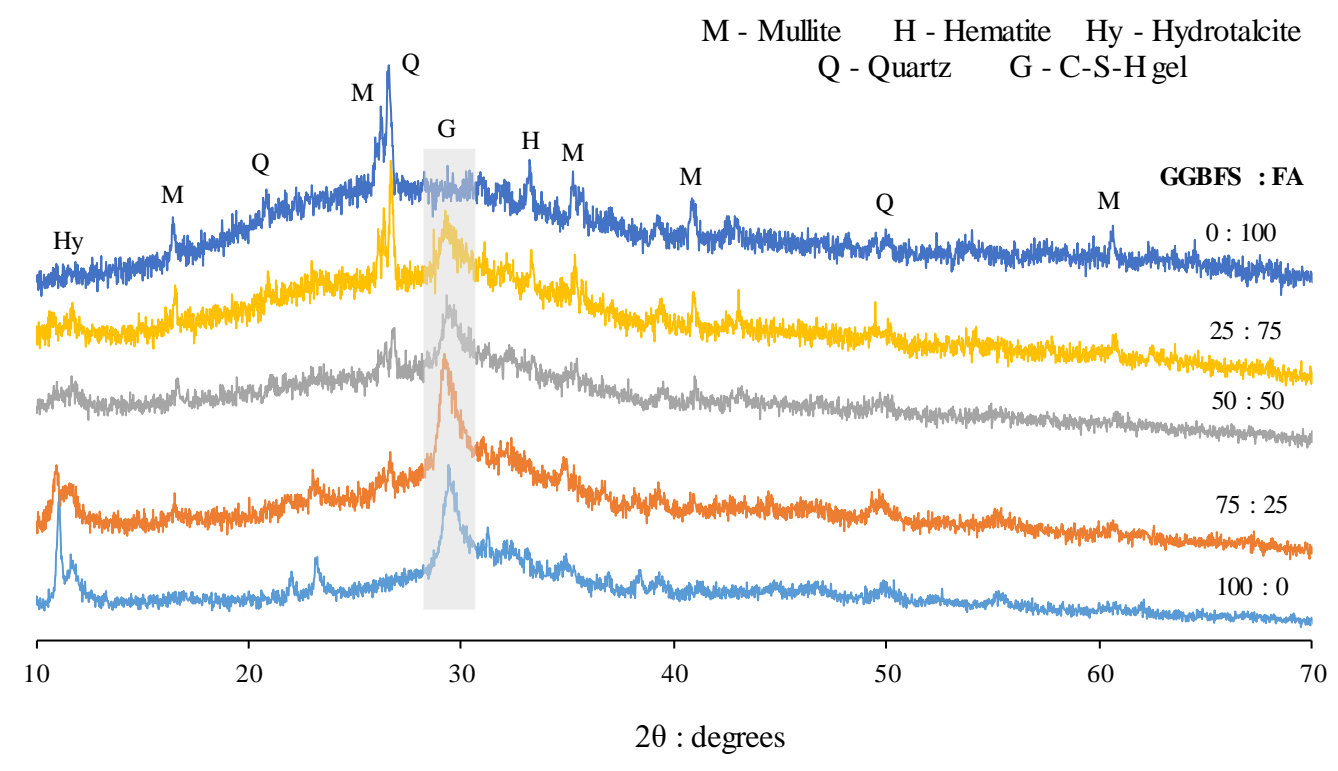

Fig. 6 - XRD patterns of slag/fly ash blends activated with sodium hydroxide (5M).

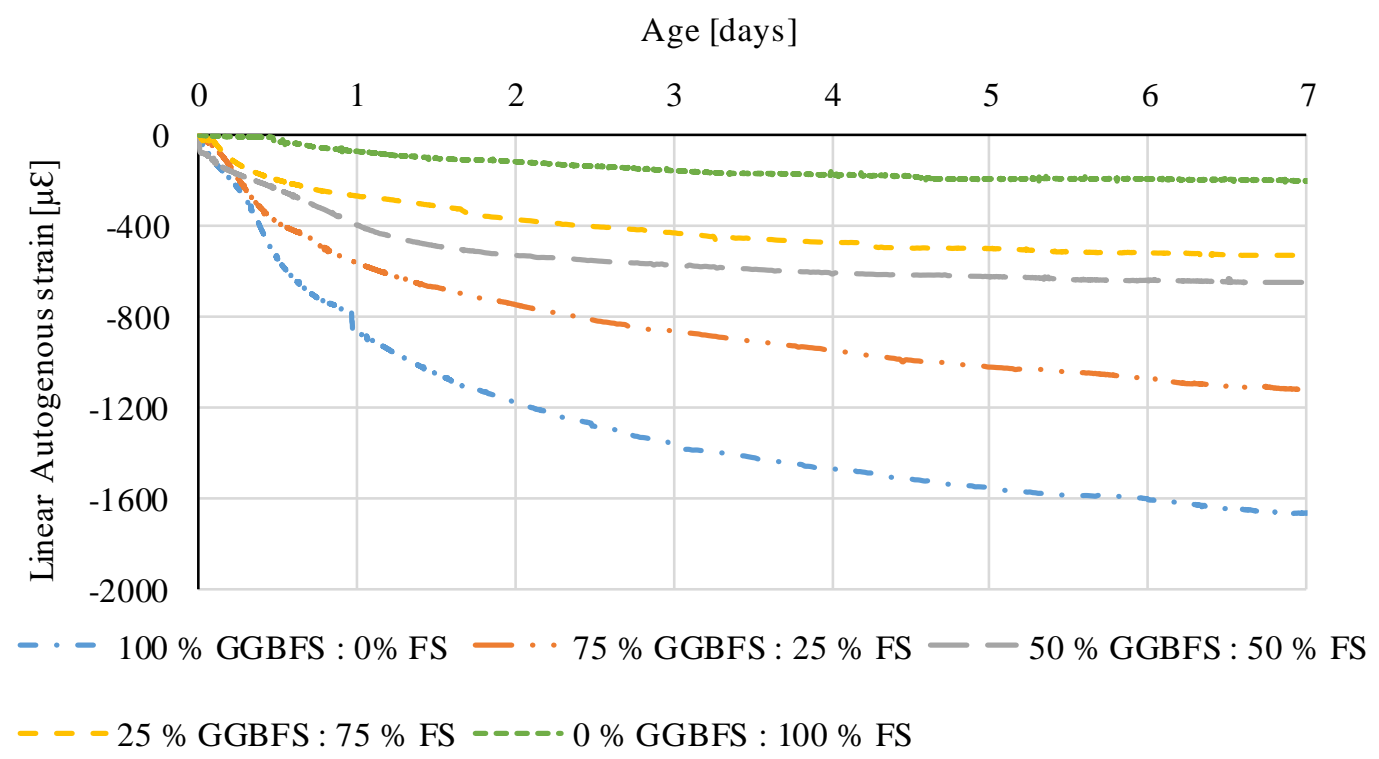

Fig. 8- Autogenous shrinkage with sodium hydroxide + sodium silicate (series: 1). 


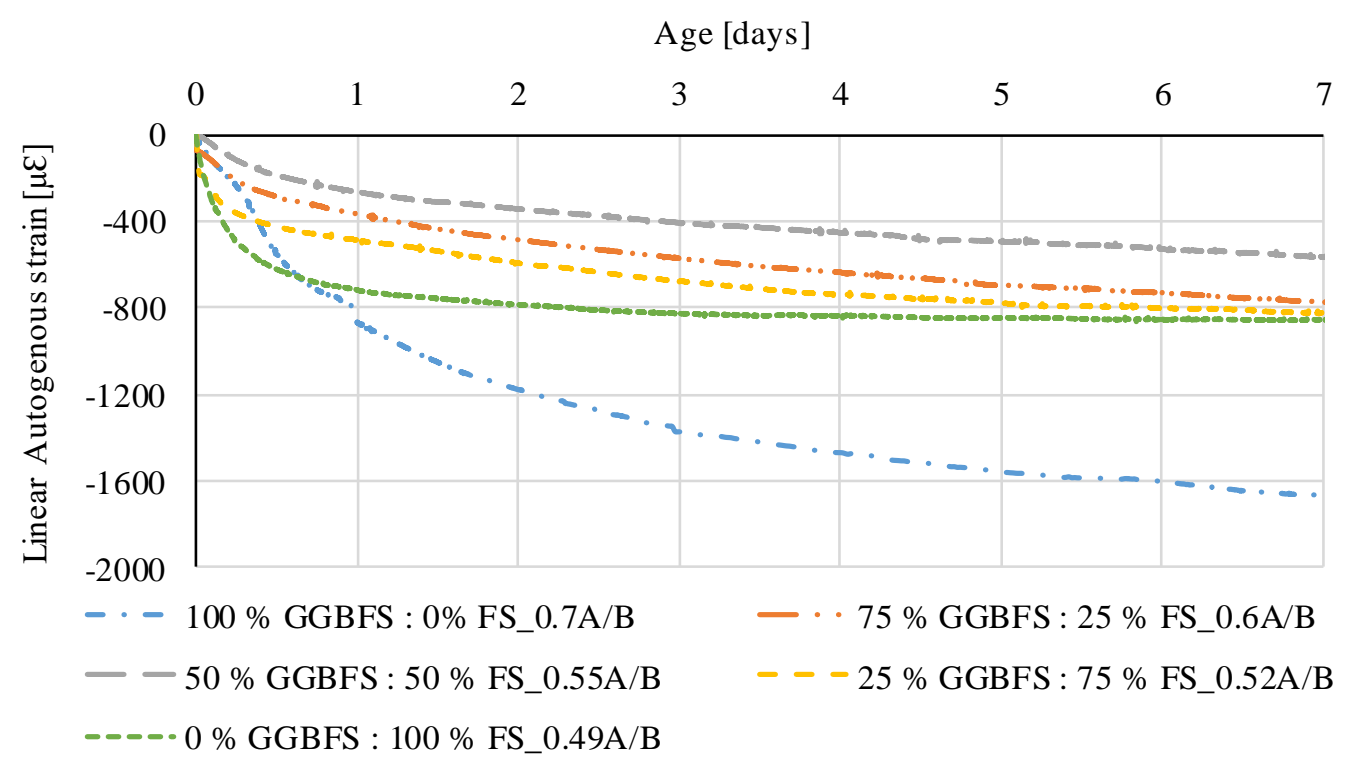

Fig. 9- Autogenous shrinkage with sodium hydroxide + sodium silicate (Series: 2).

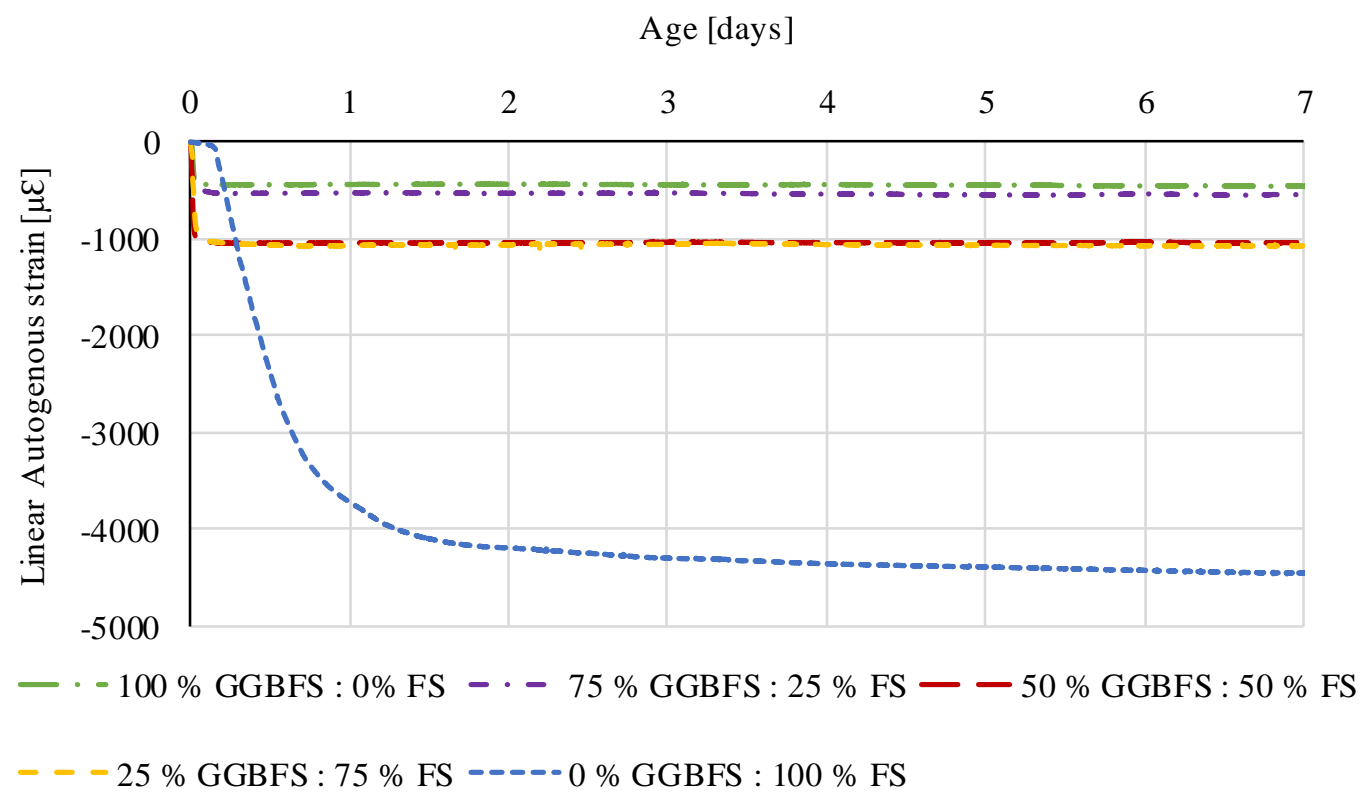

Fig. 10- Autogenous shrinkage with sodium hydroxide (Series: 3). 